victim of dyspepsia and mal-assimilation, for faintness, and sinking sensations, etc.

The one who cannot sleep finds, especially if the cause of insomnia is mental worry, that alcohol is to him a true hypnotic. As an ancesthetic, alcohol is very pronounced, and in degree will relieve pain as much as opium, chloroform, or ether. The older surgeons recognized this fact, and before the days of modern anæsthesia alcohol was used for this purpose. The laity have found out long since this peculiar quality of alcohol, and many victims of pain have sought relief in its anæsthetic effects.

The great lesson that all those who attempt to cure the inebriate is that his inebriety has a cause, that the inebriety itself is only a symptom of a nascent condition-as some one has said "neuralgia is the cry of a diseased nerve," so inebriety is the cry of a diseased nervous system, produced by causes acting directly or indirectly upon it. "Tolle Causam," the motto of every practitioner in dealing with all forms of disease, should also be the motto of every specialist on inebriety. A careful analysis of the cases of inebriety presented to us would show that there are many cases directly traceable to causes or diseased conditions that can be removed, and upon which the inebriety depends. It is the duty of every specialist on inebriety, every physician who would deal successfully with such cases, to trace out and eradicate the cause of the disorder. We cannot remove the cause in all cases; we cannot eradicate hereditary tendencies or certain lesions of tissue resulting from disease or injury; but, in many instances, we can relieve the patient of a painful or exhausting disease and thus cure his inebriety or other form of narco-mania.

\section{MEDICAL CASES IN THE COURTS.}

BY HENRY A. RILEY, ESQ.

OF NEW YORK.

THE DANGEKS OF FOREIGN IMMIGRATION.

The steamship companies are making a hard fight to avoid the penalties imposed for violations of the recent law passed by Congress against undesirable immigration. The United States officials have refused to allow a considerable number of pauper and vicious immigrants to land, and the agents of the steamship companies claim that it is a hardship to be obliged to care for them until they can be sent back. The conclusive answer of the Government is that the law is clear on the subject, and the companies should not have brought the unhealthy, insane, vicious and pauper immigrants whom it is desired to shut out. If they are brought, any expense connected with their return must be paid by the steamship companies. The figures of immigration are somewhat start- ling, and the arrivals from countries where the immigrants are of the most undesirable classes show the largest totals.

The countries of Southern Europe are now outstripping Great Britain and Germany in the number of arrivals. During $1890,40,883$ persons arrived from Russia, 29,994 from Hungary, 62,492 from Italy, and 19,737 from Poland. It would be one of the alleviating circumstances of the disgraceful massacre at New Orleans if it checked in whole or in part the present inundation of Italian immigrants. There is hardly any problem connected with the duties of Health Boards which is so serious and so perplexing as how to deal with the insane and sick foreigners who crowd the steerages of the ocean steamships. It seems difficult to devise a practicable scheme for inspection in foreign ports, and it will perhaps only be a heavy pecuniary loss which will teach the steamship companies to exercise some supervision themselves. It is proposed, among other things, to photograph all rejected immigrants, so as to see that they do not slip in at some later time.

\section{COSMETICS AND SPECTACLES IN COUR'T.}

There have been various attempts in New York to convict of illegally practicing medicine a famous dealer in cosmetics, face washes, etc., whose advertisements, consisting mainly of his own face, are to be found in journals all over the country, but his business seems to go on thrivingly. It is somewhat difficult to distinguish clearly where the line between business and professional dealings lies in such cases, but we think it would be a wise stroke of policy if the aforesaid face washer were to become the bona fide holder of a medical diploma by a conscientious course of study at some reputable medical school.

In this connection it may be noted that the optician holds a somewhat doubtful position in regard to the practice of medicine. If he furnishes a customer glasses to cure errors in sight, does he practice medicine so as to run counter to the law requiring the possession of a license? If he investigates the troubles of the eye, determines the errors in refraction and prescribes a combination of lenses such as will remedy the affection, has he crossed the line which makes him an offender in the eye of the law? The French courts have recently held to the narrow, technical theory, and have decided that it is illegal for an optician to give pathological information on the state of the eyesight and to prescribe for any visual trouble a combination of lenses. The optician may be a physiologist, but cannot do anything to remedy the troubles he discovers. It is not unlikely that a broader principle of legal construction would be adopted in this country if the question arises, as it may at any time, concerning the status of opticians. 
STEAMBOATS AND CEME'TERY VAUI'TS ARE NO'T BUILDINGS.

A New York court holds that where the Civil Damage Law forbids the selling of liquor under certain circumstances in a "building or premises," it does not apply to a steamboat where liquor is sold. The learned judge likened the steamboat to a vault in a cemetery, which he said was not a "building" in the sense meant by the statute against burglary, although it might be above ground.

\section{PIGEON SHOOTING IS NOT CRUEL IN PENNSYLVANIA.}

A Pennsylvania statute provides that any person who shall wantonly or cruelly ill-treat, overload, beat or otherwise abuse any animal shall be deemed guilty of a misdemeanor, but the Supreme Court has just held that this does not apply to a member of a gun club who, at a pigeon shooting match, shoots at and wounds a pigeon set loose from a trap, if it is immediately killed when its wounded condition is made known. The Court said :

From the facts found by the jury, the defendant has merely been punished for want of skill. It is doubtless true that much pain and suffering is often caused to different kiuds of game by the unskilfulness of sportsmen. A squirrel badly wounded, may yet crawl to its hole and suffer for many hours or days and die. So with birds. They are often badly wounded and yet manage to get away only to suffer. It was not pretended that the Act applied to such cases. The sportsman in the woods is not responsible for the accuracy of his aim under the Act of 1869 . At the same time it is manifest that much suffering would be spared wild game if sportsmen were better trained. Skill in shooting upon the wing can only be gained by practice. It is not so with inanimate objects. There accuracy of aim can be acquired by shooting at a mark. It is conceded that the sportsman in the woods may test his skill by shooting at wild birds. Why then may he not do the same with a bird confined in a cage and let out for that purpose? Is the bird in the cage any better or has it any higner rights that the bird in the woods? Both were placed here by the Almighty for the use of man.

In accordance with this reasoning a conviction in the trial court was set aside.

\section{MEDICAL PROGRESS.}

\section{Therapenties and Pharmacology}

TREATMENT OF TYPHLITIS. - In the earliest stage, absolute rest in bed, entirely liquid food, and a sedative mixture are necessities. I have generally used the liquor opii sedativus (B. P.), and occasionally joined with it some tincture of belladonna; nepenthe has also proved very val. uable on two or three occasions. If the pain be very severe, a hypodermic injection of morphine will relieve it for a time, and I have found it disappear "for good" after one injection. A mustard-leaf may be applied to the seat of the pain, and followed up by a linseed poultice every two hours, or a hot fermentation or spongiopilin if the poultice be too heavy. A few drops of brandy or other spirit sprinkled on the flannel on the side which will touch the skin often takes away pain successfully. It is well in two or three days' time to administer a fair-sized enema of soap and water, and unless the bowels are moved of themselves, this had better be repeated daily. With ordinary care it is quite harmless; it removes whatever may be in the sigmoid flexure, and it stimulates the colon to get rid of its contents, thus probably helping to empty the cæcum and withdrawing the cause of the inflammation. If the vomiting is troublesome, an effervescing mixture with hydrocyanic acid or small doses of lime-water, will be useful. For diet, a little broth, or beef-tea, or arrow-root, or Benger's food, given every two hours in two or three ounce doses will suffice. Milk I regard as not very good food in these cases; unless it be freely diluted with soda-water or lime-water, it is too apt to become a mass of hard curds in the stomach, which may prove very irritating to the inflamed bowel. With the cessation of pain, the lessening of the lump in the groin, and the general improvement in the patient, of course an improved diet and some changes in the medicine become needful. Bismuth, I have generally found to be serviceable in the later stage going on to convalescence. With the surgical varieties into which typhlitis may stray, I will not deal here, as I have no personal experience of them, nor will I touch on that debated question, removal of the appendix. - Archives of Pediatrics.

'The EFFect of Certain Drugs on the Renal Circulation.-Dr. Albanese has published in an Italian journal some important researches on the effects of caffeine, chloral, and curare on the circulation in the kidney, by which he has been led to the conclusion that the amount of urine secreted is not directly proportional to the quantity of blood passing through the organ. When chloral alone was given there was a very marked increase in the volume of the kidney, though, as is well known, this drug has an exceedingly slight diuretic action; while curare, which has a marked diuretic action, was shown to cause no perceptible increase in the volume. When caffeine was introduced into an animal already under the influence of either chloral or curare, it immediately caused a decided increase in the size of the kidney, and at the same time induced marked diuresis. Nevertheless, the increase in size produced under these conditions was not enough to account for the large quantity of urine secreted. Dr. Albanese does not agree with Schroeder that caffeine contracts the renal vessels, but finds that its action is first to increase slightly the volume of the organ and then to 